\title{
A Field Study on Urban Rail Transits In City Of Kuala Lumpur: Passenger Views On Train Noise And Vibration
}

\author{
Mohd Idrus Bin Mohd Masirin ${ }^{1}$, Nur Farrina Johari ${ }^{2}$, \\ Noor Hafiza Nordin ${ }^{3}$, Abdul Halid Abdullah", Mohd Isom Azis ${ }^{5}$ \\ ${ }^{1,2,3,4}$ Faculty of Civil and Environmental Engineering, Universiti Tun Hussein Onn Malaysia, 86400 \\ Parit Raja, Malaysia, Batu Pahat \\ 1idrusmas@gmail.com, ${ }^{2}$ rineashi@gmail.com, ${ }^{3}$ fieyza.nordin@gmail.com, ${ }^{4}$ halid@uthm.edu.my, \\ 5isom@prasarana.com.my
}

Keywords: Comfortability, Noise, Vibration, LRT, MONOREL,

Malaysia is a fast developing country which thrives on the growth of its population and economy. Kuala Lumpur is the capital of Malaysia with an area of $243 \mathrm{~km}^{2}$ has a population of 1.4 million [1]. From the statistics, the number of passengers using intercity train services in Malaysia in was $187,345,149$ in the year 2012 [2]. Comfortability of a service is a major factor that influences the public. The research will be conducted at the City of Kuala Lumpur, PUTRA LRT (Kelana Jaya Line) and MONOREL Line is selected as the main focus of the research. The data collection will be conducted in the train coaches with two parameters. The noise and vibrations in the train coaches will be taken using the Sound Level Meter (NOR118) and Vibration Meter (Movipack 01dB-Steel) respectively. The noise data were obtained from the interior of the train coaches during operation, while the vibrations were obtained from the wall surface of the coach interior. The vibration aspect for this research is more focused on three parameters which are displacement $(\mu \mathrm{m})$, vibration velocity $(\mathrm{mm} / \mathrm{s})$ and vibration frequency $(\mathrm{Hz})[7]$. Questionnaires were given out to the train passengers in order to obtain public opinions and satisfaction feedbacks relating their experiences on the train coaches. In this paper it also discusses on the outcomes of the field research work conducted and it was found that PUTRA LRT has a lower vibration value when compared to the MONOREL. The public opinion has also showed unanimous agreement to the field observations conducted by the researchers. However, MONOREL records lower noise levels compared to PUTRA LRT which means quieter journey experience to the commuters. It is hoped that this study will enable the operators to enhance their service weaknesses with the public playing a part in improving the urban rail transit in the City of Kuala Lumpur.

\section{Introduction}

The research on the comparative analysis of train coach and vibration of LRT (Light Rail Transit) and Monorail will show and create a better understanding of the our train services standpoint in the eye of the public. This created an opportunity to learn the shortcomings and gives a better visualization on the comfortability of the train services. It is critical for finding out whether the noise level and their vibration levels directly or indirectly causes significant amount of discomfort for the train's passengers. From the vibration levels, the paper would be able to determine whether it directly or indirectly influence the noise in the respective train coach. With comparing the PUTRA LRT (Light Rail Transit System) and MONOREL System used in the city of Kuala Lumpur, the level of discomfort and quality of services for each train services can be determined and extracted for better visualization. But with this also, the quality of service and comfortability for the train users should be taken into account. From the vibration produced in the train coach, it will greatly cause a significant amount of discomfort among the passengers. The vibrations on the walls of the coach will show that the level of discomfort projected towards the passengers. These are the paper's objectives; first to identify the causes of train coach noise and vibrations for Putra LRT and Monorail services in the City of Kuala Lumpur. Then to determine and critically analyze the selected rail transit system and the noise and vibration levels generated during its services. Finally to conduct correlations between types of train services, the levels of train coach noise \& vibration levels. This paper purpose was to study the train coach noise and vibration 
between PUTRA LRT (Light Rail Transit System) and Monorail in the city of Kuala Lumpur for the urban rail transportation network. This research includes the rate of noise levels and the vibration levels for both of the train service. The two parameters would undoubtedly correlate with level of comfort for the passengers and their satisfactory ratings on the train services. With this, the comfortability of the passengers on the train's services will directly influence their decisions on reusing the services and recommending them to others. The selection of the two trains provides the comparatives values as there are different in their technical and construction methods. The paper showed the method that was used will be conducted using field observations on site for the data collection, along with giving out questionnaires to passenger for their feedbacks and interviews to respective train personnel for a better understanding of the train's schedule and service's time interval. It is to be determining factor that the train services are adequately amenable to the needs of its users and its comfortability aspects towards its passengers. It seems that, if the noise of the train increases, it can be seen that the vibration in the train coaches might also increases.

\section{Literature Review}

The service quality of the public transport in that area seems unsatisfied and average level, which physical facilities in term of cleanliness and comfortableness, frequencies and responsiveness of the driver of the public transports. [3] The PUTRA LRT (Kelana Jaya Line) is one of the three rail transit lines in the Kuala Lumpur Rail Transit System. The vehicle may be large - comparable to subway car-or small- a cabin for a few passengers. [4] Monorail uses an electrified third rail to power cars that provide all-day service at frequent intervals. The train operates within the city, typically with stations placed a mile or less apart. Monorail (MONOREL) is the most expensive kind of service kind of service to build and is limited to large cities that can support the high initial cost of underground tunnel or elevated tracks and electrification. [5] Monorail moves throughout the city on a suspended rail tracks made of concrete.

There are many discomforts in Railway Transportation. Comfort is a relative feeling. It depends to person experiencing it, what they have been through that time, what they are feeling. In order to accurately know what those make people tick and feel discomfort is quite difficult. To identify the users comfort for a service, the method to use is by questionnaire study. He have identified the parameters involved and created questions and found out that people have expressed their satisfaction in the train services in Malaysia. The parameters include both the vibrations in coach and also the noise in the coach. These two plays an important role in creating discomfort among the passengers. Noise. Sounds, particularly loud ones that would disturb people or make it difficult to hear wanted sounds are considered noise. As noise is derived from sound, it is also considered as noise pollution that would happen when projection of excessive sound happened at an undesirable area. [6] Noise means any unwanted sound. The types of sound that might effect a person's comfortability when the train is in operation are human voice, the frictions that produced sounds in the coach, sound from the movements of the coach and also the voice of the operator when making an announcement.[7] However, the sounds in the coach when operating are almost impossible to segregate to the sources. This is why this study is done by collecting the sound level data as a group. The data collected in this study have to be made up of those collective sounds from various sources. To measure the noise level, the unit used is the $\mathrm{dB}$ (decibel). This unit is used worldwide and commonly used to measure sound and noise. Decibel is a unit of measure on a logarithm that will show the value of sound pressure from a surrounding or produced from specific source. The device used for measuring the sound level is the Sound Level Metre. The decibel scale is made up of a large sum of pressure that it can be detected and heard by the human ears. It would be at a range of $0-160 \mathrm{~dB}$. The zero scale determines the minimum value that a normal human being can detect and the $1 \mathrm{~dB}$ scale states the smallest change that can occur in the sound pressure.

Vibration. The vibration that occurs in a train coach is sometimes not noticeable to the passengers, but there are also times that the vibration tremors can be felt by the passengers. When the vibration is felt, the levels are determined whether the tremors would be felt throughout the body or on at the 
place in contact. The vibrations are commonly felt in the train coaches but rarely noticed by the passengers and neglected its implications to the people. The vibration on a surface uses Vibration Meter. Vibration and noise are intricately connected to each other, as both produces waves and frequency that cannot be seen. In terms of comfort, the vibrations would create waves or frequency on the surrounding space of the coach. Eventhough there are different aspects for the parameter, it has something in common, that is both have waves or frequency. Sound is the vibration of air. The vibrations hit your ear drum in your ear. Sound produces waves that then turn into what we perceive as noise. This is how vibrations are turned into what we hear in our ears, as being talking, loud bangs, trains, and so on. The standard frequencies for Malaysian trains are between $1-80 \mathrm{~Hz}$, these are the most ideal value. [7]

\subsection{Materials and Methods}

The flow chart provided will show the flow of the research work from start to finish. With referring to the flow chart below, the work process will be shown clearly. Below is the methodology flow chart.

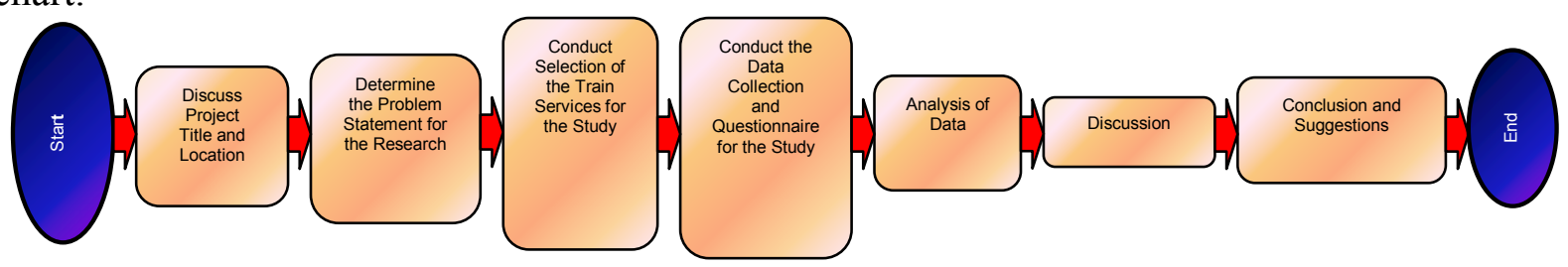

Figure 3: Methodology Research Flow Chart.

Data Collection and Observations. The vibrations from the walls varies, as the people leaning to them will experience the tremors directly whilst people just standing will gain the effect of vibration indirectly. The vibration level can be used continuously throughout the 10 stations of the train's route. To determine the noise level in the train coaches during the duration of the travel, the use of a decibel detecting device is critical. The pictures that showed the research work done is seen in Appendix A.

Questionnaire Design. After the data collection is completed on both PUTRA LRT (Light Rail Transit) and MONOREL with all the parameters accounted for, then it is time to conduct the questionnaire to the train's passengers. Passenger feedback is an element that was used to perceive the passenger opinion and then as a verification in determining the level of passenger comfort in coach for the research. In the two topic, will comprises many other subtopic that will include the noise disturbance, suitable noise level, the soundproofing in the train coach, loudness of the train, the 'shakiness' of the train, vibration disturbance, level of vibration on the walls, noticeable vibration and the overall comfort level in the train's coaches.

Method for Data Analysis. The analysis is to derived and show the significance between the noise and vibration that occurs in the train coaches. From the Vibration Meter, the vibration rate from the coach can be observe and properly assessed. The vibration meter produced a graph that shows the influx of vibration velocity during the train in operation. The vibrations on the walls are analyzed separately and then they were compared. It was taken with corresponding noise level data. The noise data collected were the highest value at stations omitting the operator's and passenger voices in the coaches. As the two vibration rates are established, it will be evaluate with the noise data corresponding of the train coaches. With this the questionnaire result would be yield as a verification for the end result of which of the trains system have a better level of comfort.

Results and Discussions. The research conducted in the PUTRA Light Rail Transit (LRT) and MONOREL focuses on the surrounding noise levels and also the vibration levels on the surfaces of the interior of the coaches. The Vibration Analyzer transmitter was placed onto the walls constantly throughout the journey. The vibrations readings taken were separated into 10 parts according to the stations of both PUTRA LRT and MONOREL railway transportation system as well as the noise 
data. The vibration aspect for this research is more focused on its three parameters that were displacement $(\mu \mathrm{m})$, vibration velocity $(\mathrm{mm} / \mathrm{s})$ and vibration frequency (Hertz). All these three parameters are the main criteria for the vibration elements. The noise data were obtained from the Sound Level Meter taken during the trains were in operation. By riding the trains, the sound level and vibrations that occurred in the trains can be identified. For PUTRA LRT, there was a high screech noise that occurred at particular bends of the tracks. As for the MONOREL, although there was not much noise but the vibrations and its movements of the train was significant. The screeching sound of metal against metal or concrete was not exactly the cause of noise. It also causes some concern to the passengers. At some point the tremors can be felt and influence the passenger's stature. In order, to determine and critically analyze the selected rail transit system and the noise and vibration levels generated during its services the two services were compared. As seen in Figure 4 and Figure 5 the two train tracks frequency values can be compared with the highest frequency was at $161.87 \mathrm{~Hz}$, along the Chow Kit heading towards Medan Tuanku for MONOREL whilst the highest frequency was at $163.44 \mathrm{~Hz}$, along the Pasar Seni heading towards KL Sentral PUTRA LRT.

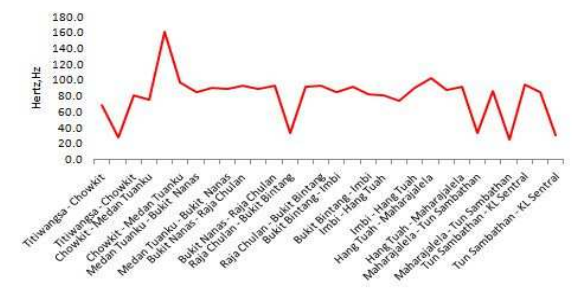

Figure 4 : Graph of $\mathrm{Hz}$ over the Stations (MONOREL)

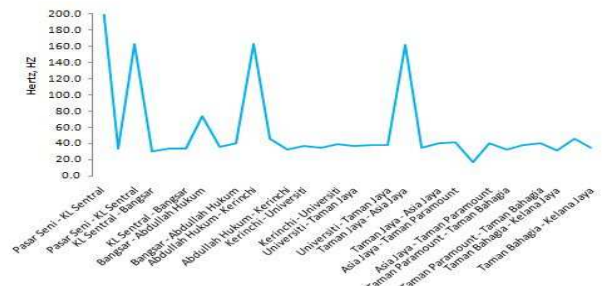

Figure 5: Graph of $\mathrm{Hz}$ over the Stations (PUTRA LRT)

Figure 6 and Figure 7 showed the comparisons between the two trains' services vibration velocity, as can be seen during the route, Maharajalela heading to Tun Sambathan the vibration velocity, $0.2489 \mathrm{~mm} / \mathrm{s}$ is the highest for the MONOREL services. It can also be seen during the route, Asia Jaya heading to Taman Paramount, the vibration velocity, $0.204 \mathrm{~mm} / \mathrm{s}$ is the highest for PUTRA LRT. In Figure 8 and Figure 9, the significant difference between the two train's services noise level were demonstrated. It states that the highest noise level in the train was during the route from Titiwangsa to Chow Kit, with $80.3 \mathrm{~dB}$ (A) for MONOREL services and the highest was at Bangsar to Abdullah Hukum, $87 \mathrm{~dB}$ (A) for the PUTRA LRT.
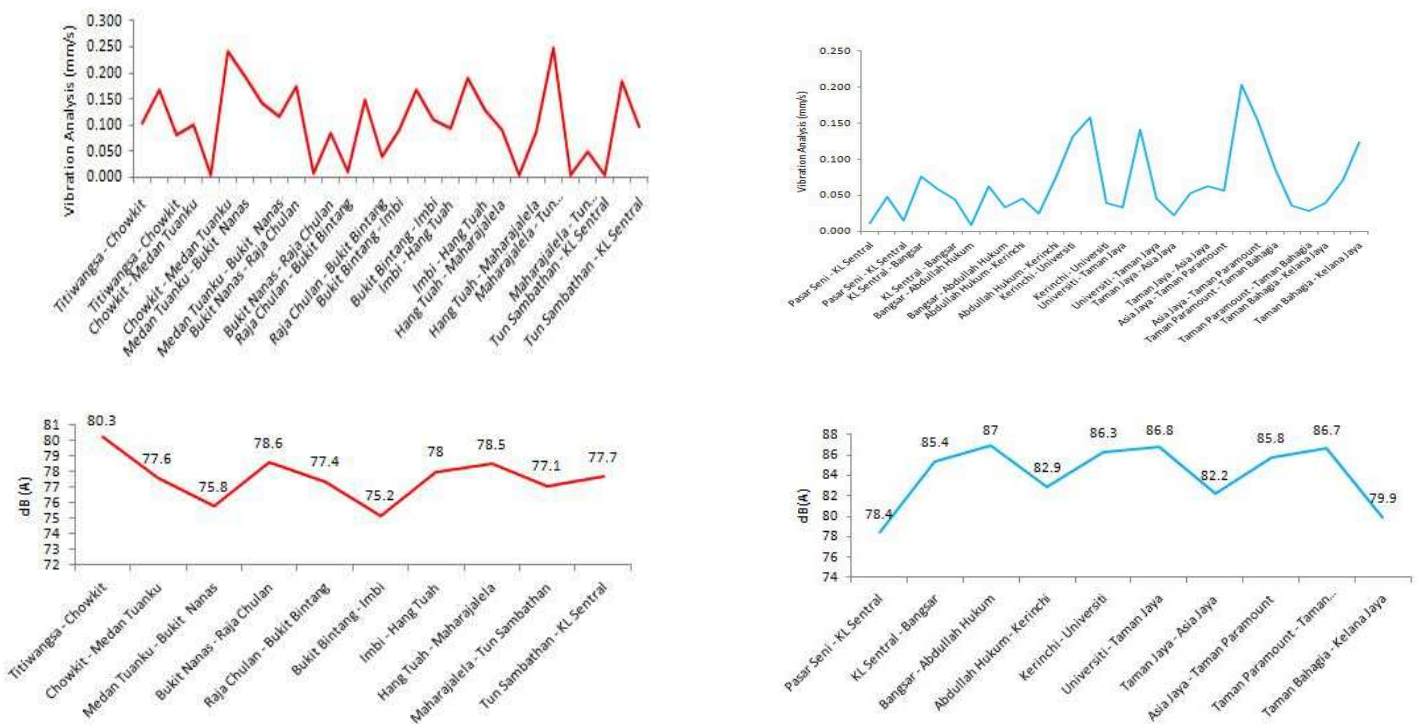

Figure 8: Graph of $d B(a)$ over the Stations (MONOREL)

Figure 9: Graph of dB (a) over the Stations (PUTRA LRT) 
Then to finally the researcher conduct correlations between different types of train services, the levels of train coach noise \& vibration levels. On the types of the trains, there were differences in the operating route length and also the coach number for both PUTRA LRT and MONOREL services. For the MONOREL, it is a smaller size coach and also only has two cars whilst for the PUTRA LRT it is larger in size and also has double the amount of cars during operation. When in operation, the MONOREL moves upon a single suspended beam track making it to be fast and kind of unstable during turns. As for the PUTRA LRT, it is suspended and the tracks are larger in size than the MONOREL. Due to this the PUTRA train was be more stable and would not be as precarious during turns. Thus, there is a correlation on the types of train services and also its levels of noise and vibration. As previously stated, the MONOREL is more shaky due to it track, making the vibrations highly felt and its frequency higher than the standard required for Malaysian trains. Even though the PUTRA LRT services are shaky and have a high frequency level but the vibrations were not felt. For the noise levels in the trains, the PUTRA LRT is higher than MONOREL. It occurred at turn which have higher friction. This ultimately causes the noise level to spike and uncomfortable to passengers.

To ultimately determine the better trains' services between the two is by verification via questionnaire. The questionnaire was divided into three parts; standing/sitting, noise, vibration. The bar charts showed that the passengers were more comfortable sitting and standing in PUTRA LRT while in operation. The bar chart states $80 \%$ feels more comfortable standing in PUTRA LRT than the $8 \%$ those that feels comfortable standing in MONOREL. the bar chart states that more percentage of passengers are more comfortable standing in a PUTRA LRT train as opposed to standing in a MONOREL train. 88\% feels more comfortable standing in PUTRA LRT than the $42 \%$ those that feels comfortable standing in MONOREL. For the MONOREL it seems that many of its current passengers were unhappy with the vibrations and agree with $86 \%$ of passengers stating that the vibration affects their comfortability as opposed to the only $16 \%$ of passengers that agree that the vibration in PUTRA LRT train effects their comfortability. For the MONOREL it seems that a few of its current passengers were unhappy with the vibrations and agree with $10 \%$ of passengers stating that the vibration affects their comfortability as opposed to the $86 \%$ of passengers that agree that the noise in PUTRA LRT train effects their comfortability. It can be concluded that the PUTRA LRT is the more comfortable train service between the two train services.

\section{Conclusion and Recommendations}

From the results above, it can be concluded that the PUTRA LRT while have more satisfactory better with standing and sitting condition and many people are more comfortable with the vibration level and condition. Noise is big part of discomfort mainly because they are totally noticeable. MONOREL though falls short in the questionnaire attains a small victory over PUTRA LRT due to its somewhat quiet train services. With this, can be said that over all the PUTRA LRT has a high level of comfort than the MONOREL due to the high satisfactory percentage. PUTRA LRT subsequently produces the least vibration out of the two train services. It stands out on all three sub parameters, vibration velocity, displacement and velocity frequency that are obtained from the (Vibration Meter) via the vibgraph software. MONOREL only lost out by a small margin. However, from the research, it was determined that between the two train services, MONOREL have a quieter travel experience than PUTRA LRT. It is hoped that in-depth research on reducing the effect of vibration of noise can be conduct for better in-coach train comfortability. 


\section{References}

[1] Saporna, G. C. \& Claveria, R. A. \& Geetha, S, "Foreigners' Satisfaction on the Country's Rail Services and Its Impact on Their Stay in Malaysia," Tourism Research \& Hospitality, pp 1-4, 2012.

[2] Department of Statistics Malaysia, "Buletin Bulanan," Department of Statistics Malaysia, 2013.

[3] Zakaria, Z. \& Hussin, Z. \& Abdul Batau, M. F. \& Zakaria, Z, "Service Quality of Malaysian Public Transports," Cross-Cultural Communication, vol. no. 6 (issue no. 2), pp 84 - 90, 2010.

[4] Grava, C, "Urban Transportation System Choices for Communities," United States of America: McGraw -Hill Education, 2002.

[5] Subramaniam, M, "Analysis of Quality Response Service Time of Intercity Train Services at Kluang Railway Station,” Universiti Tun Hussein Onn Malaysia: Undergraduate Thesis, 2012.

[6] Mat Lazim, S.H.I. (2005), "Kajian Kebisingan Lalu Lintas di Kawasan Sekolah dalam Bandar Batu Pahat," Universiti Tun Hussein Onn Malaysia: Undergraduate Thesis, 2005.

[7] Nordin, Noor Hafiza, "Analisis dan Penentuan Indeks Tahap Keselesaan Koc bagi Sistem Pengangkutan Rel Transit di Bandaraya Kuala Lumpur," Universiti Tun Hussein Onn Malaysia: Bachelor Thesis, 2014. 